\title{
SPINOCEREBELLAR ATAXIA TYPE 6 IN BRAZIL
}

\author{
Hélio A.G. Teive', Renato Puppi Munhoz', Salmo Raskin², Lineu César Werneck ${ }^{1}$
}

\begin{abstract}
Spinocerebellar ataxia type 6 (SCA 6) is an autosomal dominant cerebellar ataxia caused by CAG repeat expansion in the SCA6 gene, a alpha 1A voltage-dependent calcium channel subunit gene on chromosome 19p13. SCA-6 is characterized predominantly by slowly progressive pure cerebellar ataxia with late onset. We report three index patients, with pure, late onset, cerebellar ataxia, belonging to three different Brazilian families, all of them with Japanese ancestry, from Hokkaido island of Japan.
\end{abstract}

KEY WORDS: spinocerebelar ataxia type 6, autosomal dominant cerebellar ataxia, pure cerebellar ataxia, CACNA1A gene.

\begin{abstract}
Ataxia espinocerebelar tipo 6 no Brasil
Resumo - Ataxia espinocerebelar tipo 6 (AEC6) é uma ataxia cerebelar autossômica dominante causada por uma expansão repetida do tripleto CAG no gene da AEC, que é uma sub-unidade do canal de cálcio voltagemdependente alfa1A localizada no cromossomo 19p13. A AEC6 é caracterizada predominantemente por quadro de ataxia cerebelar pura, com início tardio, e evolução lentamente progressiva. Relatamos três pacientes índices, com ataxia cerebelar pura, de início tardio, pertencentes a três diferentes famílias brasileiras, todas com ancestrais japoneses, oriundas da ilha de Hokkaido.
\end{abstract}

PALAVRAS-CHAVE: ataxia espinocerebelar tipo 6, ataxia cerebelar autossômica dominante, ataxia cerebelar pura, gene CACNA1A.

Spinocerebellar ataxias (SCA) are a genetically heterogeneous group of nearly 30 distinct genetic forms of dominantly inherited neurodegenerative disorders affecting the cerebellum and its afferent and efferent connections'. In 14 of them, the underlying mutations have been identified, with Machado-Joseph disease (MJD), also known as SCA type 3 (SCA3), been the most common worldwide, with prevalence among families with dominantly inherited ataxias ranging from $3 \%$ in central Japan ${ }^{2}$ to $63 \%$ in Portugal and Brazil ${ }^{3}$. Other forms such as SCA 1, SCA 2, SCA 6, SCA 7 and SCA 8 also have wide prevalence range depending on the ethnic background of the population studied ${ }^{1,4}$.

SCA 6 is caused by abnormal expansions of a trinucleotide CAG repeat in exon 47 of the CACNA1A gene localized on chromosome 19p13, which encodes the alpha1A subunit of the $\mathrm{P} / \mathrm{Q}$-type voltage-gated calcium channel $\mathrm{I}^{5-}$ 7. Mutations in the CACNA1A gene cause allelic disorders such as, episodic ataxia type 2 (EA-2), familial hemiplegic migraine (FHM), severe progressive ataxia with episodic features, cerebral oedema and coma after trauma, late- onset episodic ataxia and spinocerebellar ataxia type $6^{8}$. In SCA 6 the CAG repeat expansion is translated into an elongated polyglutamine tract in the carboxyl terminus of the alphal ${ }^{A}$ subunit ${ }^{9-12}$. Alleles of neurologically normal subjects carry 5 to 19 repeats, while affected patients usually show 20 to 25 CAG repeats ${ }^{2,10-12}$. Typically the age of onset is late, often in the sixth decade of life but ranging from the early 20 's to late $80^{\prime} s^{5-7,10}$. From a phenomenological standpoint, the disorder is characterized by mild but slowly progressive cerebellar ataxia, dysarthria, nystagmus, decreased muscle tonus and minimal vibratory and proprioceptive sensory loss. The hallmark of the disease is gait ataxia, which is invariably the initial symptom, remaining as the chief symptom throughout the clinical course. Tendon reflexes are normal or slightly increased and extracerebellar symptoms, such as pyramidal or extrapyramidal tract signs, ophthalmoparesis, or decreased superficial sensation, are not seen ${ }^{5-7,10,12}$.

We present the clinical and genetic studies of three unrelated Brazilian patients with SCA 6 .

${ }^{1}$ Movement Disorders Unit, Neurology Service, Hospital de Clínicas, Federal University of Paraná, Curitiba PR, Brazil; ${ }^{2}$ Genetika Laboratory, Curitiba, PR, Brazil.

Received 7 April 2008, received in final form 14 July 2008. Accepted 30 July 2008.

Dr. Hélio A.G. Teive - Rua General Carneiro 1103/102 - 80060-150 Curitiba PR - Brasil. E-mail: hagteive@mps.com.br 


\section{METHOD}

\section{Patients}

A total of 296 patients from 100 independent Brazilian families with a clinical diagnosis of autosomal dominant cerebellar ataxia (ADCA) were analyzed. All subjects were followed at the Movement Disorders Unit, Service of Neurology, Federal University of Parana. In addition to the SCA6 locus, the SCA1, SCA2, SCA3, SCA7, and SCA10 loci were also analyzed. Informed consent for research purposes was obtained from all patients involved in the study approved by the research ethics committee.

\section{Molecular studies}

Genetic analyses were performed by Genetika Laboratory (Curitiba-PR) and genomic DNA was extracted from blood lymphocytes by standard methods as previously described ${ }^{13}$. Polymerase chain reaction (PCR) was also performed on a PTC-200 Thermal Cycler (Perkin Elmer, USA) using the primers S-5-F1 and $S-5-R 1{ }^{11}$. Alleles were amplified and analyzed on polyacrylamide gels using standard electrophoresis methods. To determine the exact repeat length, we used highly denaturing electrophoresis conditions. To know the number of CAG repeat, we formed a standard curve according to the size of DNA marker and migration rate of an unknown DNA fragment, thus we can fill the migration rate of different bands in the curve to know the length of an unknown DNA fragment ${ }^{11,14}$.

\section{RESULTS}

Of the 100 families with ADCA, 3 patients from 3 families $(4.48 \%$ ) were found to be carriers of pathogenic SCA6 repeat expansions. The SCA1 mutation was detected in 2 families (2.98\%), the SCA2 mutation in 5 families (7.46\%), the SCA3 mutation in 46 families (68.66\%), the SCA7 mutation in 3 families (4.48\%) and the SCA 10 mutation in 8 families (11.94\%). The remaining 33 families (33\%) remained undiagnosed.

\section{CASES}

\section{Patient 1}

A 52-year-old Brazilian woman, with Japanese ancestry (her parents came to Brazil from Hokkaido/Japan), was referred for evaluation of a 9-year history of progressive gait disorder and sense of momentary imbalance and light-headedness triggered by rapid body movements. Symptoms were slowly progressive and associated with disequilibrium and slurred speech without vertigo. She denied paroxysmal symptoms or migraine. Her father, aged 75 years, lives in Japan and has the same problems starting at the age of 43 . The patient has 3 younger brothers with neurological symptoms at this point. Neurological examination showed bilateral gaze-evoked horizontal and vertical nystagmus and dysarthria. Deep tendon reflexes were mildly increased in the lower limbs, with no signs of spasticity, and flexor plantar reflexes. There was ataxia involving the limbs and predominantly the gait. Computed tomography showed moderate cerebellar atrophy. Genotyping of the SCA6 gene demonstrated a heterozygote expansion with 24 CAG repeats in one allele and 12 in the normal allele. Buspirone (10 mg TID) produced a mild improvement of gait ataxia.

\section{Patient 2}

A 67-year-old Brazilian woman, with Japanese ancestry (from Hokkaido/Japan), was referred for an evaluation for balance and gait difficulties. Her symptoms have been present for the last 7 years, with insidiously progressive gait ataxia with mild limb incoordination. There are no additional symptoms. The patient has five younger siblings (two sisters and three brothers) with no neurological symptoms, but her mother, and grandmother had similar gait difficulties. The patient's mother died in Japan, at the age of 70 years old, presenting gait ataxia for more than ten years. Neurological examination showed bilateral horizontal gaze-evoked nystagmus, ocular dysmetria and dysarthria; severe gait ataxia associated with less prominent truncal and appendicular ataxia. Brain magnetic resonance imaging (MRI) showed marked cerebellar atrophy. Genotyping of SCA 1, SCA 2 and SCA 3 showed no abnormalities but SCA6 gene had a heterozygous expansion with 20 CAG repeats in one allele and 13 on the other. Therapy with buspirone ( $40 \mathrm{mg} /$ day) and physical therapy did not bring any improvement of motor symptoms.

\section{Patient 3}

A 49-year-old Brazilian man, with Japanese ancestry, presented with a 5 year history balance difficulties, dizziness, and gait disorder. As in the two previous cases, symptoms were slowly progressive and after two years he began to notice slurring of speech, worst postural instability with falls and mild dysphagia. The patient's father had a similar history starting in his 50's, as well as 5 paternal uncles and his paternal grandfather, who lived and died in Japan (Hokkaido Island). Neurological examination 5 years after symptoms onset revealed moderate dysarthria, bilateral horizontal gaze-evoked nystagmus and mild gait ataxia with no additional extracerebellar signs. MRI showed moderate cerebellar atrophy. Genotyping of SCA1, 2, 3, 7, 8 and 10 genes showed no abnormalities but he had a heterozygous repeat expansion (24 CAG repeats) at the SCA6 gene. This patient was also started on buspirone $30 \mathrm{mg} /$ day with mild improvement of gait ataxia.

The clinical features of each patient described are summarized in Table. 
Table. Summary of clinical features, neuroimaging and molecular genetic testing.

\begin{tabular}{lccc}
\hline & Patient 1 & Patient 2 & Patient 3 \\
\hline Age at examination (yr) & 52 & 67 & 49 \\
Age at onset (yr) & 43 & 60 & 44 \\
Disease duration (yr) & 9 & 7 & 5 \\
Gait ataxia & + & + & + \\
Apendicular ataxia & - & + & - \\
Nystagmus & + & + & + \\
Dysarthria & + & + & + \\
Dysphagia & - & - & - \\
Episodic ataxia & - & - & - \\
Migraine & - & - & - \\
Pyramidal signs & - & - & - \\
Peripheral neuropathy & - & - & - \\
Dystonia & - & - & + \\
Parkinsonism & - & + & 24 \\
Cerebellar atrophy (CT/MRI) & + & + & + \\
CAG repeat expansion & 24 & & + \\
Descendents of families from Hokkaido/Japan & + & - & - \\
\hline & & + & - \\
\hline
\end{tabular}

\section{DISCUSSION}

Previous studies of Brazilian patients with SCA have shown that the most frequent molecular diagnosis is SCA 3 representing $73.5 \%$ of the cases tested positive, followed by SCA 10 (11.8\%), SCA 2 (7.4\%), SCA $7(4.4 \%)$ and SCA $1(2.9 \%)^{15}$. SCA 6 is relatively uncommon with prevalences of $1.8 \%$ in the Trott et al. ${ }^{16}$ study and $1.5 \%$ in the Teive et al..$^{15}$ study. These figures are low in comparison with the estimated frequencies of this disorder in Australia (30\%), Japan (28 $\%)$, Germany (22\%), Korea (19\%), and in the USA $(15 \%)^{1,7,18}$.

SCA 6 is traditionally described as a progressive, slowly, pure cerebellar ataxia with late onset. Owning to this relatively mild phenotype and late onset, some patients with this disorder may occasionally be viewed as sporad$\mathrm{ic}^{5-7,10}$. On the other hand, a number of case reports have described additional clinical manifestations in patients with a molecular diagnosis of SCA 6, such as episodic ataxia, dystonia, parkinsonism, mild pyramidal signs and neuropathy ${ }^{5,7,19}$. Imaging studies of cases of SCA 6 usually reflect the commonly pure cerebellar phenotype, demonstrated cerebellar atrophy without brainstem or other extra-cerebellar abnormalities ${ }^{1,5-7,10}$. The cases presented here do not differ from this classical description showing late onset of pure cerebellar ataxia, with different degrees of cerebellar atrophy and carrying CAG repeat expansions ranging from 20 in a patient with age onset of 60 , to 24 in patients with ages of onset 43 and 44 .
An important epidemiological feature of these Brazilian patients is the fact that they belong to three unrelated families with Japanese ancestry, all from the province of Hokkaido, in northern Japan. The genetic spectrum of autosomal dominant SCAs in this specific geographic Japanese province has already been studied by Basri et al. ${ }^{20}$. In their analysis that included 113 families, SCA- 6 was the most frequent molecular diagnosis, followed by SCA3, SCA1, SCA2, and DRPLA ${ }^{20}$.

Although we recognize that the number of patients tested positive for SCA 6 in our sample is small, our results help validate the prevalence of genetically subtypes of SCAs based on ethnic origin and geographical variation. It would be interesting to study descendents of families from Hokkaido, Japan worldwide to find out if there is a shift in the direction of intermediate SCA 6 alleles. If this is true, this epidemiological data might help physicians and researchers worldwide when screening for molecular diagnosis of Japanese descendants with signs and symptoms of pure spinocerebellar ataxia.

\section{REFERENCES}

1. Schöls L, Bauer P, Schmidt T, Schulte T, Riess O. Autosomal dominant cerebellar ataxias: clinical features, genetic, and pathogenesis. Lancet Neurol 2004;3:291-304.

2. Shimizu Y, Yoshida K, Okano T, et al. Regional features of autosomaldominant cerebellar ataxia in Nagano: clinical and molecular genetic analysis of 86 families. J Hum Genet 2004;49:610-616.

3. Silveira I, Miranda C, Guimaraes L, et al. Trinucleotide repeats in 202 families with ataxia: a small expanded (CAG)n allele at the SCA17 locus. Arch Neurol 2002;59:623-629. 
4. Paulson HL. Dominantly inherited ataxias: lessons learned from Machado-Joseph disease/spinocerebellar ataxia type 3. Semin Neurol 2007;27:133-142

5. Jen JC. Spinocerebellar ataxia 6 (SCA6). In: Pulst SM. Genetics of movement disorders. San Diego: Academic Press, 2003:81-84.

6. Stevanin G, Dürr A, David G, et al. Clinical and molecular features of spinocerebellar ataxia type 6. Neurology 1997;49:1243-1246.

7. Geschwind DH, Perlman S, Figueroa KP, Karrim J, Baloh RW, Pulst SM Spinocerebellar ataxia type 6: frequency of the mutation and genotypephenotype correlations. Neurology 1997;49:1247-1251.

8. Jen JC, Graves TD, Hess EJ, et al. Primary episodic ataxias: diagnosis, pathogenesis and treatment. Brain 2007;130:2484-2493.

9. Kordasiewicz HB, Gomez CM. Molecular pathogenesis of spinocerebellar ataxia type 6. Neurotherapeutics 2007;4:285-294.

10. Matsumura R, Futamura N, Fujimoto $Y$, et al. Spinocerebellara ataxia type 6: molecular and clinical features of 35 Japanese patients including one homozygous for the CAG repeat expansion. Neurology 1997;49: 1238-1243.

11. Zhuchenko O,Bailey J, Bonnem P, et al. Autosomal dominant cerebellar ataxia (SCA6) associated with small polyglutamine expansions in the alpha 1A-voltage-dependent calcium channel. Nat Genet 1997;15: 62-69.

12. Ishikawa $\mathrm{K}$, Tanaka $\mathrm{H}$, Saito $\mathrm{M}$, et al. Japanese families with autosomal dominant pure cerebellar ataxia map to chromosome 19p13.1-p13.2 and are strongly associated with mild CAG expansions in the spinocer- ebellar ataxia type 6 gene in chromosome 19p13.1. Am J Hum Genet 1997;61:336-346.

13. Sambrock J, Russel DW. Molecular cloning: a laboratory manual, $3^{\text {rd }}$ Ed. New York: Cold Spring Harbor Laboratory Press, 2001.

14. Maruyama H, Kawakami H, Nakamura S. Reevaluation of the exact CAG repeat length in hereditary cerebellar ataxias using highly denaturing conditions and long PCR. Hum Genet 1996;97:591-595.

15. Teive HAG, Roa BB, Raskin S, et al. Clinical phenotype of Brazilian families with spinocerebellar ataxia 10. Neurology 2004;63:1509-1512.

16. Trott A, Jardim LB, Ludwig Ht, et al. Spinocerebellar ataxias in 114 Brazilian families: clinical and molecular findings. Clin Genet 2006;70:173-176.

17. Storey E, du Sart D, Shaw JH, Lorentzos P, Kelly L, Gardner RJM, Forrest SM, Biros I, Nicholson GA. Frequency of spinocerebellar ataxia types 1, 2, 3, 6, and 7 in Australian patients with spinocerebellar ataxia. Am J Med Genet 2000;95:351-357.

18. Lee WY, Jin DK, Oh MR, et al. Frequency analysis and clinical characterization of spinocerebellar ataxia types 1, 2, 3, 6, and 7 in Korean patients. Arch Neurol 2003;60:858-863. Note: Erratum: Arch Neurol 2003;60:1256.

19. Sethi KD, Jankovic J. Dystonia in spinocerebellar ataxia type 6. Mov Disord 2002;17:150-153.

20. Basri R, Yabe I, Soma H, Sasaki H. Spectrum and prevalence of autosomal dominant spinocerebellar ataxia in Hokkaido, the northern island of Japan: a study of 113 Japanese families. J Hum Genet 2007;52:848-855. 